\title{
Warning Method of Coal Bursting Failure Danger by Electromagnetic Radiation
}

\author{
Guang-Jian Liu, Cai-Ping Lu, Hong-Yu Wang, Peng-Fei Liu, and Yang Liu \\ School of Mining Engineering, Key Laboratory of Deep Coal Resource Mining (Ministry of Education), \\ China University of Mining and Technology, Xuzhou, Jiangsu 221116, China
}

Correspondence should be addressed to Cai-Ping Lu; cplucumt@126.com

Received 3 November 2014; Accepted 24 November 2014

Academic Editor: Shimin Liu

Copyright (C) 2015 Guang-Jian Liu et al. This is an open access article distributed under the Creative Commons Attribution License, which permits unrestricted use, distribution, and reproduction in any medium, provided the original work is properly cited.

Electromagnetic radiation (EMR) can reflect the stress state and deformation level of coal, yet its warning indexes correlated with coal properties and roof caving is poorly understood. The laboratory observations of EMR effects of coal samples bursting failure and in situ investigations in the process of roof caving are presented in this paper. EMR peak with increasing stress is discussed when the failure of coal samples happens, which provides an explanation to EMR signals positively correlated well with the stress loaded. The linearly increasing relation is also found between EMR intensity and the uniaxial compressive strength, and EMR maximum amplitudes and pulses behave a logarithmic accretion tendency with bursting energy indexes of coal. By in situ investigations, it is well found that EMR amplitude can effectively warn coal deformation and failure based on the critical value $120 \mathrm{mV}$ proposed from experiments.

\section{Introduction}

Coal/rock undergoing deformation and failure emits many forms of energy, among which is electromagnetic radiation (EMR). The electromagnetic activity that is detected during the deformation and before failure of inhomogeneous materials, such as rocks, is of particular interest. This EMR is detectable not only in the laboratory but also in geophysical scale. Cohen first proposed the term EMR in the 1920 [1]. The EMR phenomenon was first observed to occur by researchers in the USSR prior to earthquake events, and EMR from material fractured under stress was first investigated in laboratory by Stepanov in 1933 [2]. Hanson and Rowell found EMR phenomenon during rock failure [3]. Studies on EMR produced by the deformation and failure of coal and other low strength rocks in coal-bearing strata started from 1990s. EMR from rocks and other brittle materials has been extensively investigated.

Presently, the physical mechanism of EMR is still unknown. Several attempts to explain the EMR mechanism are made including the acceleration and deceleration of dislocations and the movement of charged crack sides and electrical breakdown. Unfortunately, none of these was able to explain the properties of the detected EMR [4-6].
Numerous investigations show a relationship between applied stress and EMR emitted from rock material [7-9]. Therefore, the geogenic EMR, thus, merits its classification as an important sign of rockburst triggered by stress concentration. Many observations of electromagnetic anomalies associated with coal-rock mass deformation or bursting failure have been reported. For example, Muto et al. believed that the frictional discharges might be one of the sources of the seismoelectromagnetic emission based on an experiment simulating the motion of an asperity on a fault surface [10]. Rabinovitch et al. presented a viable model of EMR, according to which EMR was emitted by an oscillating dipole created by ions moving collectively as a surface wave on both sides of rock crack [11]. Morgounov and Malzev interpreted the data of electromagnetic precursors in terms of a multiple fracture model and discussed the possibility of constructing a physical model for the generation of a quasistable field and EMR on the basis of the deformation process [12]. Wang et al. established the coal-rock EMR electromechanical coupling model and conducted a series of experiments on coal-rock samples of lower strength to study the characteristics of ultralow frequency EMR signals, which verified that EMR were well correlated with stress in coal mass [13-15]. Liu 
and He proposed an EMR model for predicting outbursts based on an experimental system composed of a differential pressure gauge and an electromagnetic field generator [16]. Jiang et al. investigated EMR of roadways to determine the zones of intensive roof deformation [17, 18]. Lichtenberger found that orientations and magnitudes of the horizontal principal stresses derived from the measurements of EMR correlated well with conventional stress measurements [19]. Mallik et al. presented an application of EMR technique for deciphering the directions of principal horizontal stress and identifying active fracture planes [20]. Carcione et al. found the shape of the grains in the rock has a significant influence on the EMR properties [21]. Frid proposed a new modern method of rock and gas outburst forecast, relying on registration of EMR caused by rock fracture, and employed an EMR method associated with rock fracture to study water infusion in rockburst-prone coal strata [22, 23]. Jiang et al. monitored the roadway nearby fault stability by the means of EMR instrument and fully obtained the coal and rock mass internal energy accumulation and release rules $[17,18]$. He et al. described EMR method as a preliminary effort to provide a tool capable of predicting the stress concentration condition in coal-rock [24]. Nardi and Caputo believed experimentally that EMR that were possibly caused by fracturing may also be used to monitor the stress conditions of rocks for geological purposes [25]. Lu et al. proposed to warn gas outburst hazard induced by coal and rock bursting failure using microseismic (MS) and acoustic emission (AE) associated with EMR [26].

The main monitoring indicators of EMR include its intensity, pulse number, and dynamic trends. At present, although coal/rock EMR has been extensively studied both experimentally and theoretically, many issues still remain unresolved, such as its characteristics, spatial distribution, affecting factors, and characteristics under different sample scales, in particular if coal/rock is under complex loading conditions.

By the experimental investigations of EMR of coal in the deformation and failure processes, the amplitude and pulse evolutionary rules along with stress were analyzed, and the relationships between EMR intensity, the uniaxial compressive strength, and bursting energy index of coal samples were revealed. In particular, the critical index of EMR amplitude was obtained to evaluate the stress concentration and rockburst danger at Longgu coal mine with weak rockburst tendency.

\section{Experiment on EMR Effects of Coal Samples Subject to Stress}

2.1. Coal Samples. 7303 working face excavates $7 \#$ seam at west panel of Longgu coal mine, where the rockburst phenomenon begins to manifest along with the increasing mining depth. According to the principle of coal samples processing, the lump coal without obvious fissures or fractures was carefully collected and sealed.

According to the standard ISRM, coal materials were drilled into samples with $50 \mathrm{~mm}$ in diameter, then sawn into about $100 \mathrm{~mm}$ high segments, and grinded precisely at both ends. Nonparallelism of both ends was required to less than $0.01 \mathrm{~mm}$, and the deviation in diameter was less than $0.02 \mathrm{~mm}$. Total $4 \Phi 50 \mathrm{~mm} \times 100 \mathrm{~mm}$ coal samples were prepared.

2.2. Test Equipment and the Corresponding Parameters. Experimental system is classified into load device and monitoring apparatus. Load device uses MTS 815 press machine which is a high-precision electrohydraulic servo material testing system. It can precisely control the loading speed, and the complete stress-strain curves of coal and rock sample deformation until failure can be clearly recorded. EMR acquisition was accomplished by Disp-24 acoustic emission (AE) workstation developed by American Physical Acoustics Corporation and EMR sensors. The system contains 24 channels, 12 of which can record waveform and analyze the real-time or postfrequency-spectrum characteristics. AE and EMR signals can be simultaneously collected by the corresponding sensors.

Total 2 channels are used, and $1 \#$ and $2 \#$ channels record $\mathrm{AE}$ and EMR signals, respectively. The preamplifier coefficients of $\mathrm{AE}$ and EMR signals both are $40 \mathrm{~dB}$. The center frequency value of $\mathrm{AE}$ sensor is $7.5 \mathrm{kHz}$, and the threshold value is $55 \mathrm{~dB}$. The center frequency value of EMR dotfrequency antenna is $20 \mathrm{kHz}$, and the threshold value is $92 \mathrm{~dB}$. The sampling rates of both $\mathrm{AE}$ and EME signals are $2000 \mathrm{kHz}$, and the sample length is $5 \mathrm{~K}$. The copper network whose dimension is less than $0.5 \mathrm{~mm}$ as the shielding system is adopted to reduce the effect of external EMR interference. During the experiment, the AE and EMR sensors and the press ram are together put into the shielding system.

Figure 1 shows the schematic arrangement of load device, $\mathrm{AE}$ and EMR sensors, and Disp-24 AE workstation. Figure 2 is Disp-24 AE data acquisition system.

In this experiment, the uniaxial loading mode was tested, and the loading rate was about $0.5 \mathrm{kN} / \mathrm{s}$ until sample failure. The complete stress-strain curves were recorded. Simultaneously, the EMR signals were recorded in the whole period of sample deformation and failure. Main measured parameters included the amplitude $(\mathrm{mV})$ and pulse $(\mathrm{N})$ of EMR signals and so forth. Figure 3 shows the photographs of LM3\# coal sample before and after failure.

2.3. Results and Analysis. Table 1 is the physical and mechanical parameters experimentally measured of 4 coal samples.

From Table 1, the uniaxial compressive strength of coal is less than $15 \mathrm{MPa}$, and the bursting energy indexes of 4 samples are less than 5 , which indicate that $7 \#$ seam belongs to weak rockburst tendency. In the experiment, the phenomenon that coal debris eject or splash intensively is not observed during the process of coal samples deformation and failure. However, EMR signals are significantly produced. Therefore, EMR can be used to warn coal-rock deformation and failure, especially the rockburst danger.

The EMR signals were collected simultaneously along with the deformation and failure of coal samples, and the main monitoring indicators of EMR include its amplitude and pulse. Figures 4, 5, 6, and 7 are the curves of stress-time, EMR amplitude-time, and pulse-time of 4 coal samples. 
TABle 1: Physical and mechanical parameters of 4 coal samples.

\begin{tabular}{lccccc}
\hline Sample label & Height/mm & Diameter/mm & Uniaxial compressive strength/MPa & Bursting energy index & Elastic modulus/MPa \\
\hline LM2\# & 98.16 & 49.12 & 6.801 & 1.182 & 3024.1 \\
LM3\# & 90.4 & 49.22 & 13.824 & 1.875 & 3572.6 \\
LM4\# & 80.68 & 49.3 & 4.622 & 1.022 & 1119.6 \\
LM5\# & 99.12 & 49.22 & 9.811 & 1.541 & 3735.5 \\
\hline
\end{tabular}

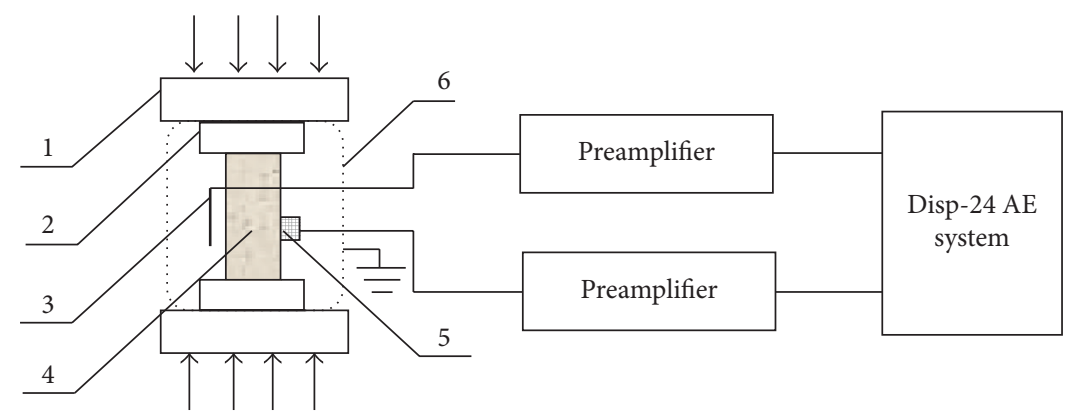
(1) MTS servo testing machine
(4) Coal and rock samples
(2) Insulation pad
(5) AE sensors
(3) Electromagnetic antenna
(6) Electromagnetic shielding

FIGURE 1: Schematic diagram of the experimental system.

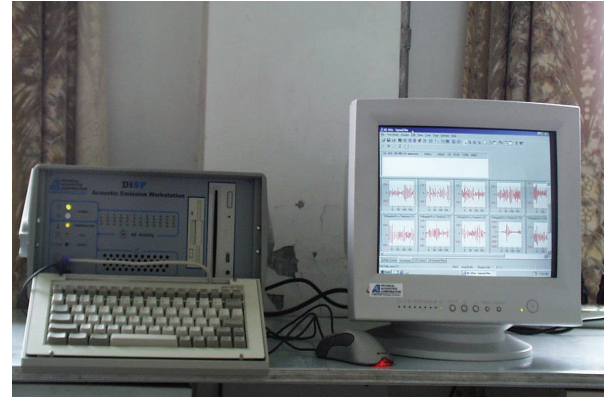

FIgURE 2: Disp-24 AE data acquisition system.

Obviously, the measured amplitude and pulse of EMR signals positively correlate well with the applied stress. In particular, when the failure of coal samples occurs, the amplitude and pulse simultaneously reach the maximum and after that gradually decrease along with the stress.

In order to further reveal EMR effects in the process of deformation and failure of coal samples, the correlations between the maximum amplitude and pulse of EMR, the uniaxial compressive strength, and bursting energy index were regressively analyzed. Figure 8 is the regressive curves of EMR maximum amplitude, the uniaxial compressive strength, and bursting energy index of samples. Figure 9 is the regressive curves of maximum pulse, the uniaxial compressive strength, and bursting energy index.

Theoretically, the amplitude and pulse of EMR increase linearly with the electron charge and acceleration of charged particles in the process of deformation and fracture of coalrock. And the amplitude and pulse of EMR are associated with the density of charged particles, the larger the particles

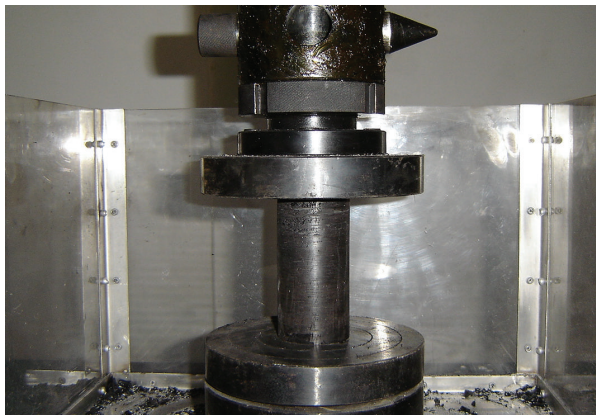

(a) Before loading

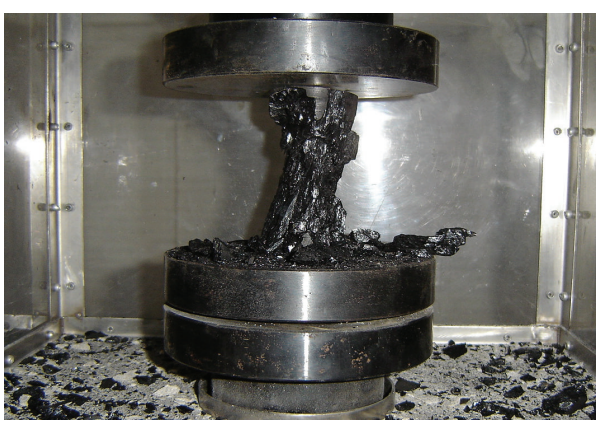

(b) After failure

FIGURE 3: Photographs of LM3\# coal sample before and after failure.

number is, and the higher the strength of EMR is. Generally, the higher the uniaxial compressive strength of coal-rock is, the more the formed microcracks is, and the larger the number of particles accumulated in the tip of microcracks per unit time is. In other words, the higher the uniaxial compressive strength is, the more the intensity of deformation 


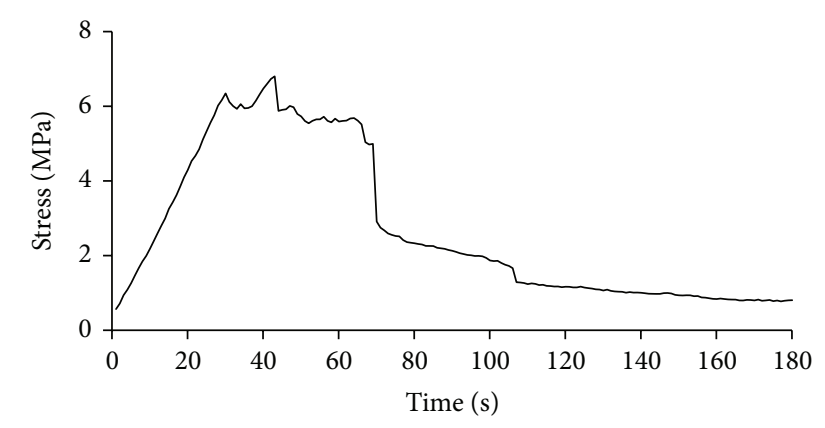

(a) Stress-time

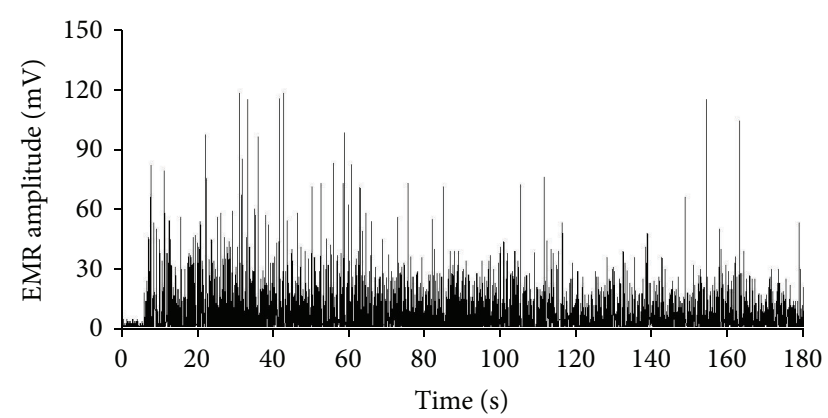

(b) EMR amplitude-time

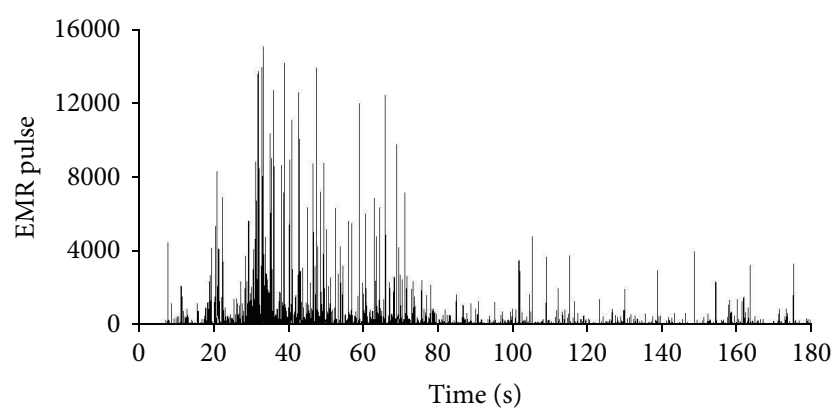

(c) EMR pulse-time

FIgURE 4: The measured stress and EMR of LM2\# coal sample.

TABLE 2: The measured maximum amplitudes of EMR.

\begin{tabular}{lcccc}
\hline Sample label & LM2\# & LM3\# & LM4\# & LM5\# \\
\hline Maximum amplitude & $118 \mathrm{mV}$ & $163 \mathrm{mV}$ & $61 \mathrm{mV}$ & $132 \mathrm{mV}$ \\
\hline Average & \multicolumn{4}{c}{$118.5 \mathrm{mV}$} \\
\hline Application index & $120 \mathrm{mV}$ \\
\hline
\end{tabular}

and failure is, and the higher the velocity and acceleration of charged particles is. So, the larger the uniaxial compressive strength of coal-rock is, the higher the amplitude and pulse of EMR are, and the greater the bursting energy indexes are. It can be found from Figures 8 and 9, when the failure of coal sample occurs, the maximum amplitudes and pulses of the EMR increase linearly along with the increasing uniaxial compressive strength values. In addition, for bursting energy indexes of coal samples, the maximum amplitudes and pulses behave a logarithmic accretion tendency with it.

In Table 2, it is shown that EMR maximum amplitude values of 4 coal samples are $118 \mathrm{mV}, 163 \mathrm{mV}, 61 \mathrm{mV}$, and

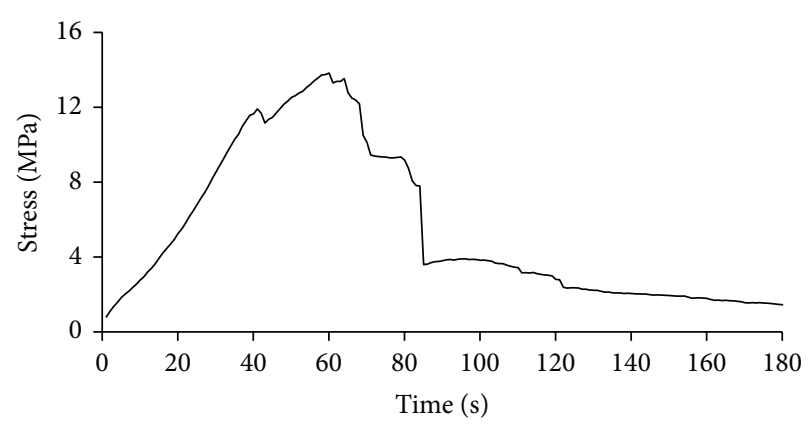

(a) Stress-time

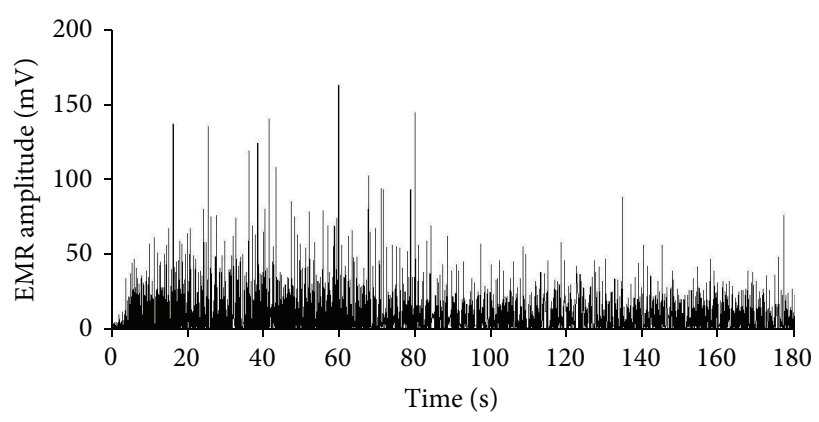

(b) EMR amplitude-time

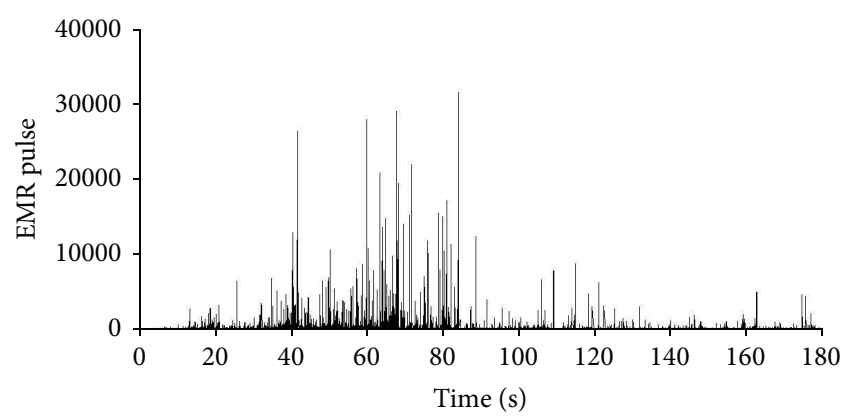

(c) EMR pulse-time

Figure 5: The measured stress and EMR of LM3\# coal sample.

$132 \mathrm{mV}$, respectively, when the failure occurs. The average (avg $\left.\left(\sum \max E\right)=118.5 \mathrm{mV}\right)$ is calculated and obtained, to propose the critical index of EMR amplitude for totally evaluating the stress state and deformation intensity of coal mass. The application index of EMR amplitude should be appropriately enlarged to be $120 \mathrm{mV}$, by taking the external inevitable electromagnetic interference in field into account.

\section{EMR Measurement in Process of Roof Caving and Subsidence}

To evaluate and warn rockburst risk of 7303 working face, EMR signal was measured in the whole mining period by KBD5 portable apparatus developed by China University of Mining and Technology (CUMT). The apparatus is mainly composed of a wideband and high-sensitivity directional receiving antenna, the mainframe and the remote communication interface, and so forth. In order to reduce the interference from other electromagnetic signals in the 


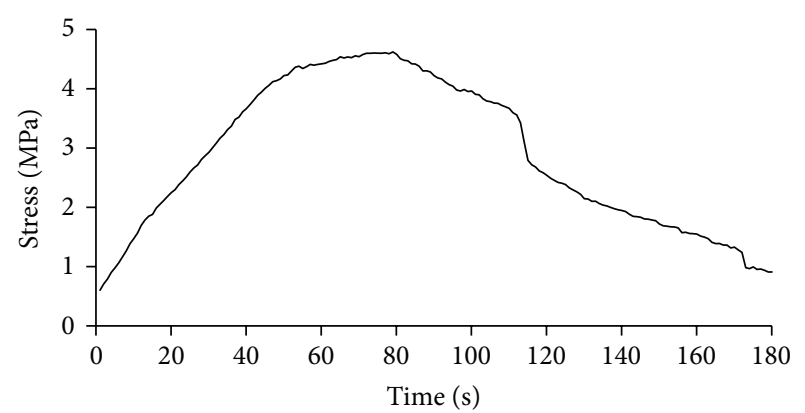

(a) Stress-time

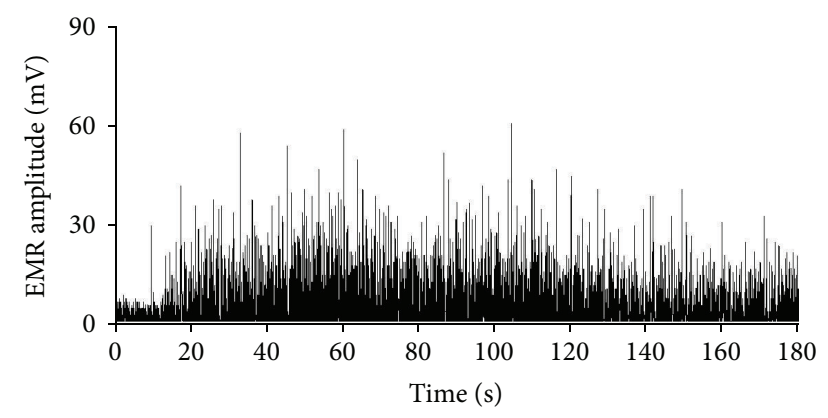

(b) EMR amplitude-time

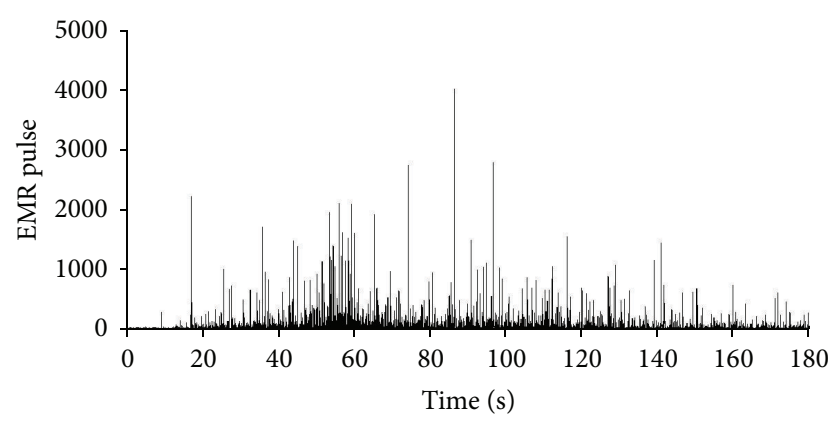

(c) EMR pulse-time

FIgURE 6: The measured stress and EMR of LM4\# coal sample.

testing environment, the antenna adopts a special shielding technique. One end of antenna is shielded and adequately grounded, which can significantly reduce the sensitivity out of the effective receiving scope and actually guarantee the monitoring reliability. Adjustable gain preamplifier is designed for the different load-electromagnetic property of coal and rock material.

A large number of studies have shown that EMR amplitude is strongly related to the level and variation of stress, especially in correspondence with sharp stress drops or the final collapse. Based on experimental conclusions and onsite monitoring experience, the critical value $(120 \mathrm{mV})$ and its variation trend (sharp drops or rises) of EMR amplitude can be used together for stress concentration evaluation in 7303 working face.

3.1. Geological and Mining Conditions of 7303 Working Face. The 7303 working face locates at the west wing of mine field, extracting 7 \# coal seam with average thickness of $4.4 \mathrm{~m}$ from August 1,2004 , and the average dip angle of $7 \#$ seam is $8-10^{\circ}$.

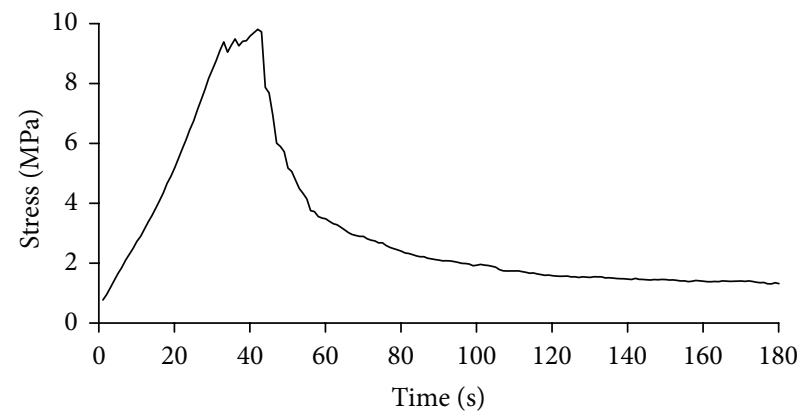

(a) Stress-time

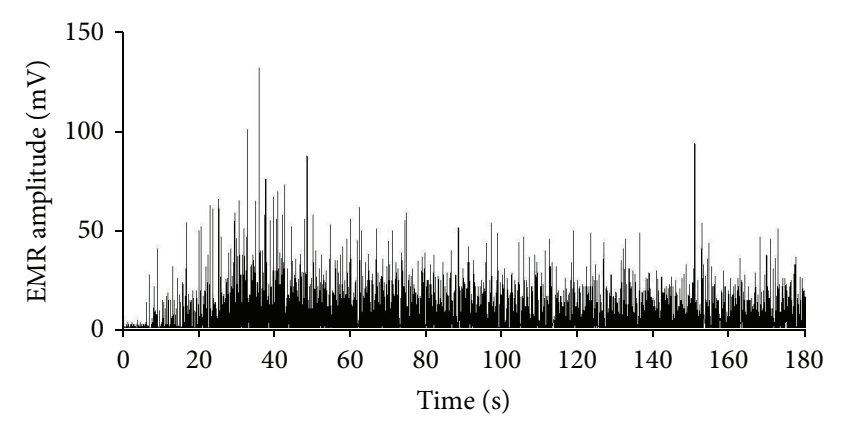

(b) EMR amplitude-time

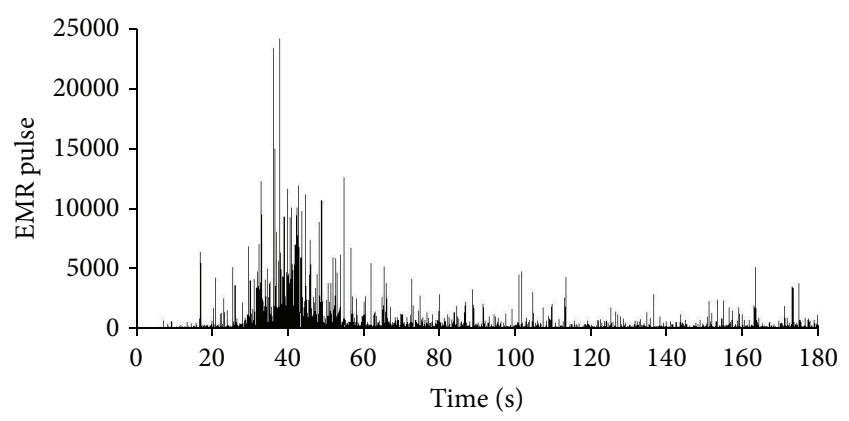

(c) EMR pulse-time

FIGURE 7: The measured stress and EMR of LM5\# coal sample.

The geological condition of working face is relatively simple, only 11 faults whose throws are between $2.0 \mathrm{~m}$ and $15.0 \mathrm{~m}$ are disclosed in 7303 working face, and the fully mechanized top coal caving mining method is adopted. As the mining depth is larger than $760 \mathrm{~m}$, there might be coal and rock dynamic disasters appearance in process of 7303 working face mining. According to the borehole data, the roof strata of 7 \# coal seam from bottom to up are as follows: siltstone $(2.0 \mathrm{~m})$, medium sandstone $(10.6 \mathrm{~m})$ so-called key stratum, siltstone $(3.3 \mathrm{~m})$, fine sandstone $(2.0 \mathrm{~m})$, and siltstone $(12.6 \mathrm{~m})$. Figure 10 shows the layout diagram of the 7303 working face.

\subsection{Monitoring Scheme}

3.2.1. Monitoring Method. For in situ measurement in coal mines, the antenna is fixed and the receiving end is vertically towards the medium-upper part of coal wall within $5 \mathrm{~m}$. The amplitude and pulse indexes and their variations of EMR are measured. The fixed monitoring points in headentry 


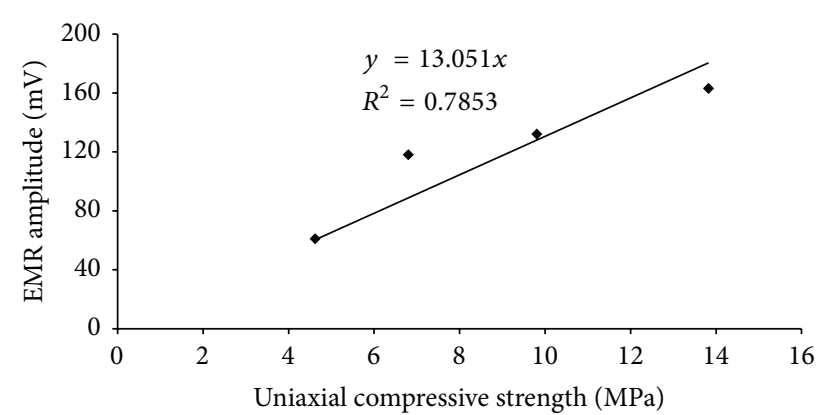

(a) Regressive curve between EMR maximum amplitude and the uniaxial compressive strength

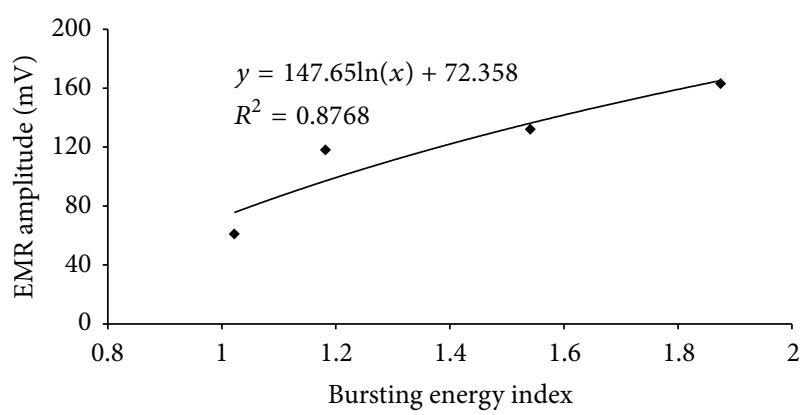

(b) Regressive curve between EMR maximum amplitude and bursting energy index

FIGURE 8: Correlations between EMR maximum amplitude, uniaxial compressive strength, and bursting energy index.

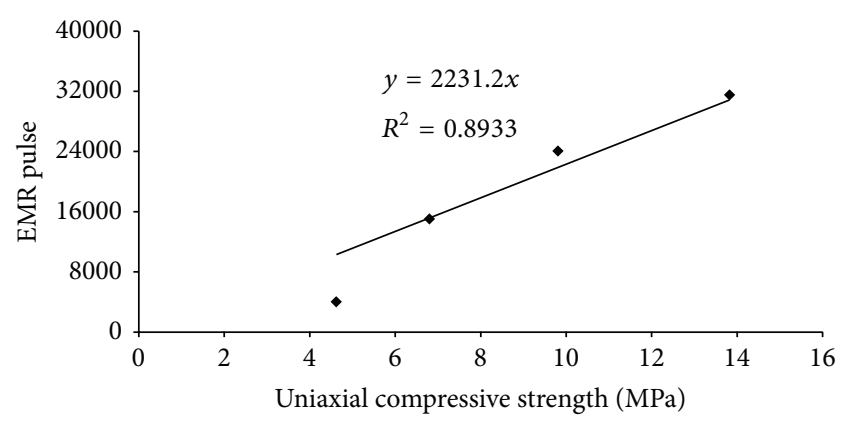

(a) Regressive curve between EMR maximum pulse and the uniaxial compressive strength

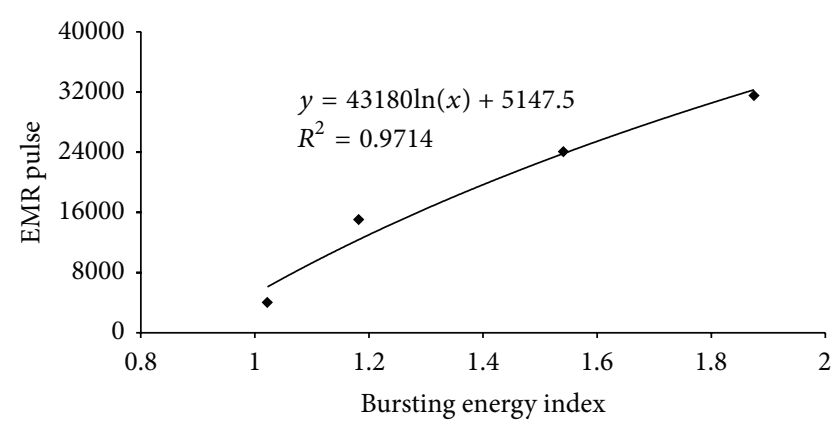

(b) Regressive curve between EMR maximum pulse and bursting energy index

FIgURE 9: Correlations between EMR maximum pulse, uniaxial compressive strength, and bursting energy index. and tailentry combined with general investigation were conducted due to the high stress concentration of roadways.

3.2.2. Arrangement of Monitoring Points. Total 12 points were outward located in headentry $10 \mathrm{~m}$ from the cut of 7303 working face, and the interval of points was principally set to be $10 \mathrm{~m}$. In addition, total 10 points were outward located in tailentry $20 \mathrm{~m}$ from the cut, and the interval of points was principally set to be $20 \mathrm{~m}$. All points will move forward correspondingly with the advance of working face, and the interval can be adjusted according to in situ observation requirements, therefore, the relative positions of which are fixed. In particular, for the rest locations characterized higher stress concentration, such as fault and roadway junction areas, the density of points arrangement should be appropriately increased.

3.2.3. Monitoring Frequency. Daily monitoring frequency is three times including morning, noon, and night shifts, and the monitoring time of each shift for one point is $2 \mathrm{~min}$.

\subsection{Conclusions and Analysis}

3.3.1. At the Stage of Initial Mining. Figure 11 shows the measured EMR amplitude variation of different points in tailentry and headentry at the stage of initial mining.

From Figure 11, it is obviously shown that the stress concentration level is not obvious and the risk of rockburst is lower due to the smaller EMR amplitude (much less than the critical value $120 \mathrm{mV}$ ), and the stress of the surrounding coal and rock of tailentry and headentry is lower. As 7303 working face firstly arranged in west panel is in the original stress state, where no any mining-induced stress interference exists. Moreover, due to the initial stage of 7303 working face mining, the fracturing and caving of overlying rock stratums do not obviously occur. Therefore, the stress concentration level of 7303 working face is relatively lower, and the monitoring value of EMR amplitude is smaller.

3.3.2. The Initial Caving of Primary Roof. On August 21, 2004, when the total advancing distance of 7303 working face reached $35 \mathrm{~m}$ so-called first caving interval, the primary roof began to fall and the pressuring process approximately lasted 2 days based on in situ observation. Figure 12 shows the EMR amplitude variation in tailentry and headentry at morning shift on August 21.

In Figure 12, compared with initial mining, the measured EMR amplitude in tailentry and headentry obviously increased, which indicated that the stress of coal and rock surrounding 7303 working face correspondingly rose due to the primary roof caving. In particular, the amplitudes of 3 monitoring points located at $42 \mathrm{~m}, 85 \mathrm{~m}$, and $105 \mathrm{~m}$ ahead of the cut in tailentry seriously exceeded the critical value $120 \mathrm{mV}$, which demonstrated that there might be rockburst risk induced by higher stress concentration. By implementing relieve-shot, EMR amplitude suddenly and sharply dropped, and the higher stress was transferred and further rebalanced. For headentry, the amplitude totally kept less than the critical 


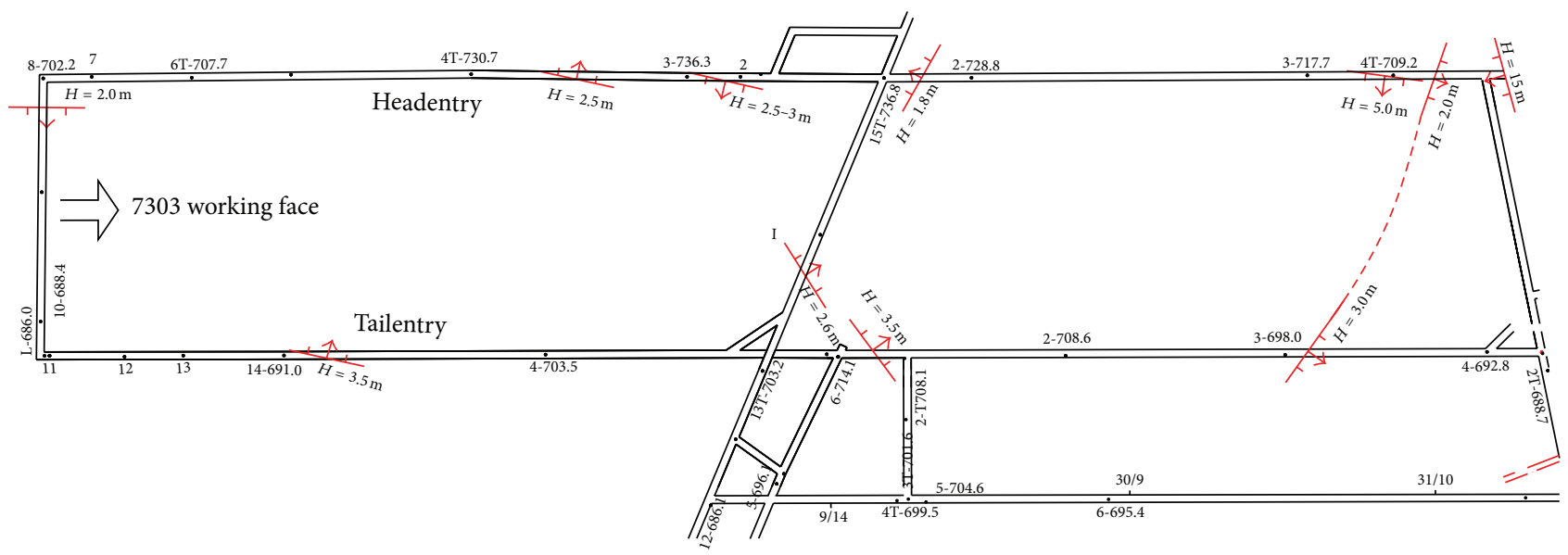

FIGURE 10: The layout diagram of 7303 working face.

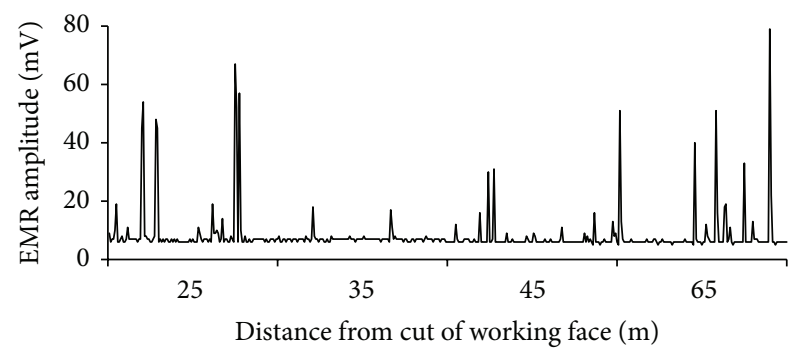

(a) In tailentry

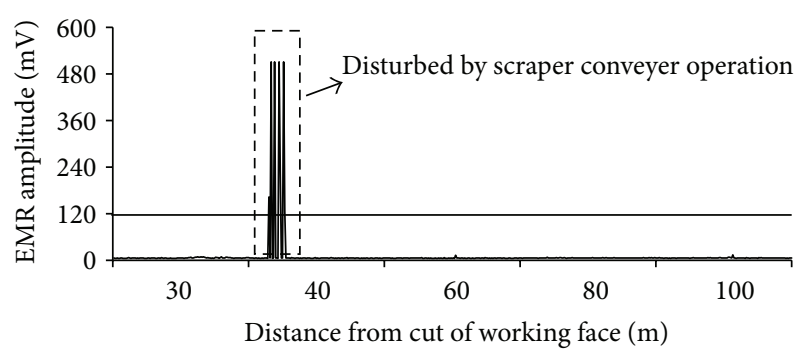

(b) In headentry

FIGURE 11: The monitoring result of EMR amplitude at the stage of initial mining.

value. Therefore, the stress of headentry was relatively smaller than that of tailentry due to its shallower burial depth.

3.3.3. The Periodic Caving of Primary Roof. Along with further advancing of 7303 working face, the primary roof will experience periodic caving process after first caving. According to the advancing distances from initial caving to first periodic caving, the caving interval of primary roof was approximately $20 \mathrm{~m}$. By the statistical analysis, the caving intervals of primary roof distributed in the range of 17 to $23 \mathrm{~m}$ based on 3 periodic caving. Figures 13-15 show EMR amplitude variations measured in tailentry at the stages of the first periodic caving, the second periodic caving, and the third periodic caving of primary roof, respectively.

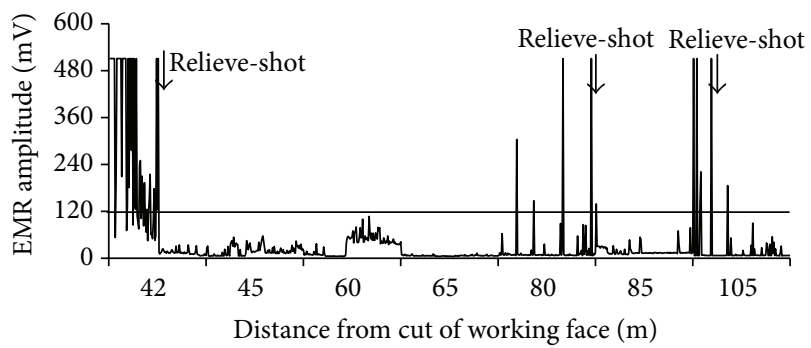

(a) In tailentry

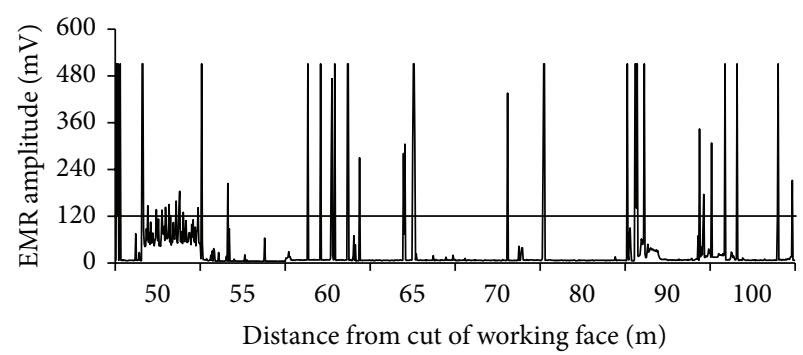

(b) In headentry

FIGURE 12: The monitoring result of EMR amplitude at morning shift on Aug 21.

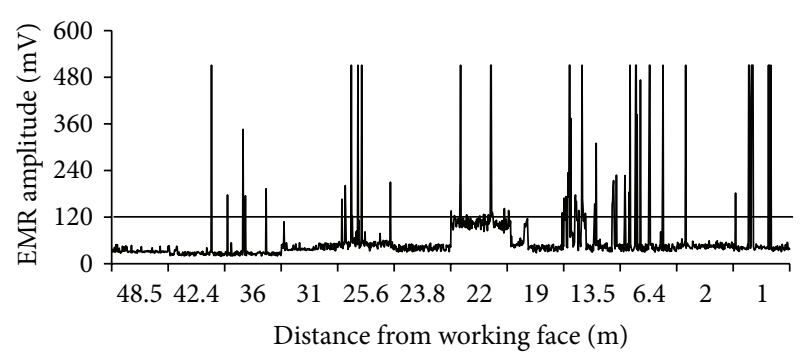

FIGURE 13: EMR amplitude variation in tailentry at the stage of first periodic caving. Note: the caving interval is $20 \mathrm{~m}$, and the pressuring intensity is not obvious according to in situ observation of roadway deformation. 


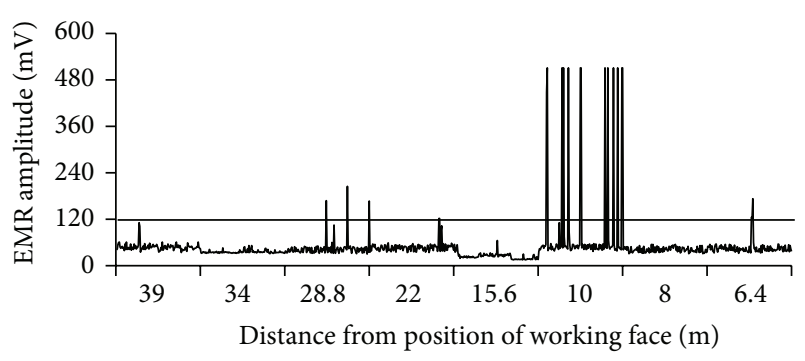

FIGURE 14: EMR amplitude variation in headentry at the stage of second periodic caving. Note: the caving interval is $17 \mathrm{~m}$, and the pressuring intensity is weaker according to in situ observation of roadway deformation.

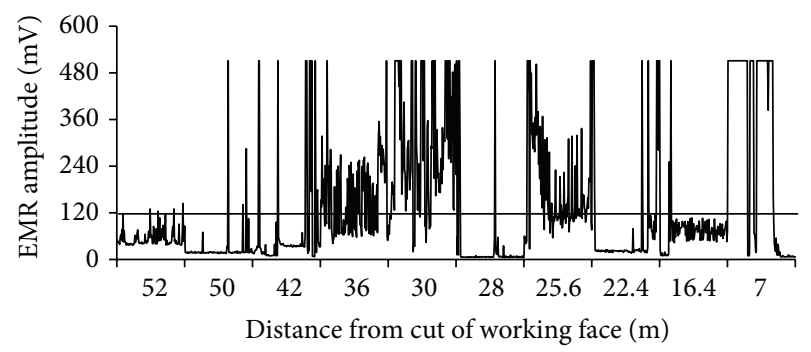

FIGURE 15: EMR amplitude variation in tailentry at the stage of third periodic caving. Note: the caving interval is $23 \mathrm{~m}$, and the pressuring intensity is stronger based on in situ observation of roadway deformation and support resistance.

In process of the first periodic caving of primary roof (in Figure 13), the overall level of EMR amplitude is less than the critical value $120 \mathrm{mV}$. However, the amplitude fluctuation is intensive within the scope of $13.5 \mathrm{~m}$ ahead of working face in tailentry, which indicates the stress concentration and the deformation and failure of coal and rock. In process of the second periodic caving (in Figure 14), the overall level of EMR amplitude is smaller than the critical value except for electromagnetic interference of the monitoring point located $10 \mathrm{~m}$ ahead of working face in headentry. For the third periodic caving (in Figure 15), EMR amplitudes of a majority of monitoring points significantly exceed the critical value. In particular, within the scope of $42 \mathrm{~m}$ ahead of working face in tailentry, the amplitude variation and fluctuation is abnormal intensive. In conclusion, based on the caving intervals and EMR amplitudes, it can be verified that EMR remarkably increases with the periodic caving interval of primary roof. In particular, the influencing range of stress concentration also increases in accordance with the periodic caving intervals. Therefore, EMR amplitude can be used to check the results of conventional pressuring monitoring and warn the risk of dynamic hazard induced by roof caving.

3.3.4. Large-Scale Movement and Subsidence of Primary Roof. From September 21 to 24, 2004, when 7303 working face advanced nearby a fault, the immediate and primary roof strata began to intensively move and subside due to the diastrophism and slippage of fault triggered by mining

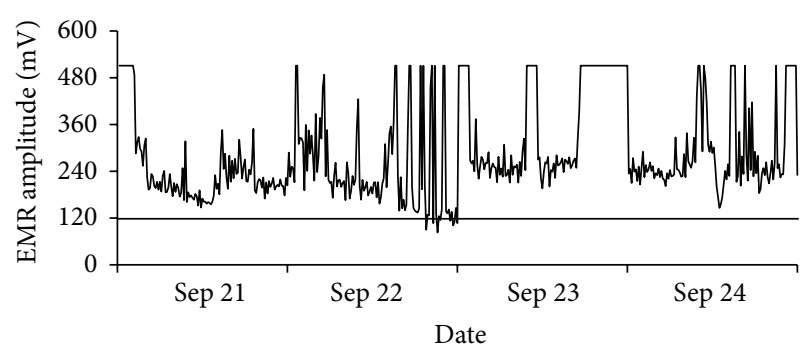

FIGURE 16: EMR amplitude of monitoring point located $20 \mathrm{~m}$ ahead of working face in tailentry from September 21 to 24 .

activity. Based on in situ investigation and measurement, it can be found that tailentry seriously deformed and part of bolts and anchor cables became invalid. Figure 16 shows EMR amplitude of the monitoring point located $20 \mathrm{~m}$ ahead of working face in tailentry.

From Figure 16, during the period of roof movement and subsidence, EMR amplitude significantly exceeds the critical value $120 \mathrm{mV}$, which indicates that the higher EMR amplitude is attributed to the violent deformation of coal and rock induced by slippage of fault. In addition, it might be confirmed that the fault can easily generate the higher stress concentration and accumulate a large amount of energy.

In summary, comparison with past investigations, the highlight of in situ measurement mainly, manifests the complete observations of EMR signals in whole period of primary roof caving in 7303 working face, such as the initial and periodic caving and the large-scale movement and subsidence of primary roof induced by tectonic stress concentration.

\section{Conclusions}

(1) The amplitude and pulse of EMR signals positively correlate well with stress. In particular, when the failure of coal samples occurs, the amplitude and pulse simultaneously reach the peak and after that gradually reduce along with the decreasing stress.

(2) The maximum amplitude and pulse of EMR increase linearly with the uniaxial compressive strength of coal and behaves logarithmic accretion tendency with bursting energy indexes.

(3) By in situ investigation of 7303 working face, it is well found that EMR amplitude can effectively reflect the stress state and rockburst failure level of coal subjected to roof loading based on the critical value $120 \mathrm{mV}$ proposed from experiments.

\section{Conflict of Interests}

The authors declare that there is no conflict of interests regarding the publication of this paper. 


\section{Acknowledgments}

The authors gratefully wish to acknowledge the collaborative funding support from the Foundation for the Author of National Excellent Doctoral Dissertation of PR China (201167), the Fundamental Research Funds for the Central Universities (no. 2014XT01), and a Project Funded by the Priority Academic Program Development of Jiangsu Higher Education Institutions (PAPD).

\section{References}

[1] L. Cohen, "Electromagnetic radiation," Journal of the Franklin Institute, vol. 177, no. 4, pp. 409-418, 1914.

[2] A. A. Urusovskaja, "Electric effects associated with plastic deformation of jonic crystals," Soviet Physics Uspekhi, vol. 11, no. 5, pp. 631-643, 1969.

[3] D. R. Hanson and G. A. Rowell, "Electromagnetic radiation from rock failure," 1982.

[4] C.-Y. King, "Earthquake prediction: electromagnetic emissions before earthquakes," Nature, vol. 301, no. 5899, article 377, 1983.

[5] A. Rabinovitch, D. Bahat, and V. Frid, "Comparison of electromagnetic radiation and acoustic emission in granite fracturing," International Journal of Fracture, vol. 71, no. 2, pp. R33-R41, 1995.

[6] A. Rabinovitch, D. Bahat, and V. Frid, "Emission of electromagnetic radiation by rock fracturing," Zeitschrift für Geologische Wissenschaften, vol. 24, pp. 361-368, 1996.

[7] V. Hadjicontis and C. Mavromatou, "Transient electric signals prior to rock failure under aniaxial compression," Geophysical Research Letters, vol. 21, no. 16, pp. 1687-1690, 1994.

[8] S. M. Krylov and N. N. Nikiforova, "On ultralow frequency electromagnetic emission from an active geological medium," Physics of the Solid Earth, vol. 31, no. 6, pp. 499-512, 1996.

[9] C. Reuther, H. Obermeyer, K. Reicherter et al., "Neotektonik und aktive Krustenspannungen in Südost-Sizilien und ihre Beziehungen zur regionalen Tektonik im Zentralen Mittelmeer," in Mitteilungen aus dem Geologisch-Paläontologischen Institut der Universität Hamburg, vol. 86, pp. 1-24, 2002.

[10] J. Muto, H. Nagahama, T. Miura, and I. Arakawa, "Frictional discharge plasma and seismo-electromagnetic phenomena," Physics of the Earth and Planetary Interiors, vol. 168, no. 1-2, pp. $1-5,2008$.

[11] A. Rabinovitch, V. Frid, and D. Bahat, "Surface oscillations-a possible source of fracture induced electromagnetic radiation," Tectonophysics, vol. 431, no. 1-4, pp. 15-21, 2007.

[12] V. A. Morgounov and S. A. Malzev, "A multiple fracture model of pre-seismic electromagnetic phenomena," Tectonophysics, vol. 431, no. 1-4, pp. 61-72, 2007.

[13] E. Wang, X. He, J. Wei, B. Nie, and D. Song, "Electromagnetic emission graded warning model and its applications against coal rock dynamic collapses," International Journal of Rock Mechanics and Mining Sciences, vol. 48, no. 4, pp. 556-564, 2011.

[14] E.-Y. Wang and E.-L. Zhao, "Numerical simulation of electromagnetic radiation caused by coal/rock deformation and failure," International Journal of Rock Mechanics and Mining Sciences, vol. 57, pp. 57-63, 2013.

[15] E. Wang, H. Jia, D. Song, N. Li, and W. Qian, "Use of ultralow-frequency electromagnetic emission to monitor stress and failure in coal mines," International Journal of Rock Mechanics and Mining Sciences, vol. 70, pp. 16-25, 2014.
[16] M. Liu and X. He, "Electromagnetics response of outburstprone coal," International Journal of Coal Geology, vol. 45, no. 2-3, pp. 155-162, 2001.

[17] Y. D. Jiang, Y. K. Lv, and Y. X. Zhao, "Principal component analysis on electromagnetic radiation rules while fully mechanized coal face passing through fault," Procedia Environmental Sciences, vol. 12, pp. 751-757, 2012.

[18] Y. Jiang, H. Wang, S. Xue, Y. Zhao, J. Zhu, and X. Pang, "Assessment and mitigation of coal bump risk during extraction of an island longwall panel," International Journal of Coal Geology, vol. 95, pp. 20-33, 2012.

[19] M. Lichtenberger, "Regional stress field as determined from electromagnetic radiation in a tunnel," Journal of Structural Geology, vol. 27, no. 12, pp. 2150-2158, 2005.

[20] J. Mallik, G. Mathew, T. Angerer, and R. O. Greiling, "Determination of directions of horizontal principal stress and identification of active faults in Kachchh (India) by electromagnetic radiation (EMR)," Journal of Geodynamics, vol. 45, no. 4-5, pp. 234-245, 2008.

[21] J. M. Carcione, G. Seriani, and D. Gei, "Acoustic and electromagnetic properties of soils saturated with salt water and NAPL," Journal of Applied Geophysics, vol. 52, no. 4, pp. 177-191, 2003.

[22] V. Frid, "Electromagnetic radiation method for rock and gas outburst forecast," Journal of Applied Geophysics, vol. 38, no. 2, pp. 97-104, 1997.

[23] V. Frid, "Electromagnetic radiation method water-infusion control in rockburst-prone strata," Journal of Applied Geophysics, vol. 43, no. 1, pp. 5-13, 2000.

[24] X. He, W. Chen, B. Nie, and H. Mitri, "Electromagnetic emission theory and its application to dynamic phenomena in coal-rock," International Journal of Rock Mechanics and Mining Sciences, vol. 48, no. 8, pp. 1352-1358, 2011.

[25] A. Nardi and M. Caputo, "Monitoring the mechanical stress of rocks through the electromagnetic emission produced by fracturing," International Journal of Rock Mechanics and Mining Sciences, vol. 46, no. 5, pp. 940-945, 2009.

[26] C.-P. Lu, L.-M. Dou, N. Zhang, J.-H. Xue, and G.-J. Liu, "Microseismic and acoustic emission effect on gas outburst hazard triggered by shock wave: a case study," Natural Hazards, vol. 73, pp. 1715-1731, 2014. 

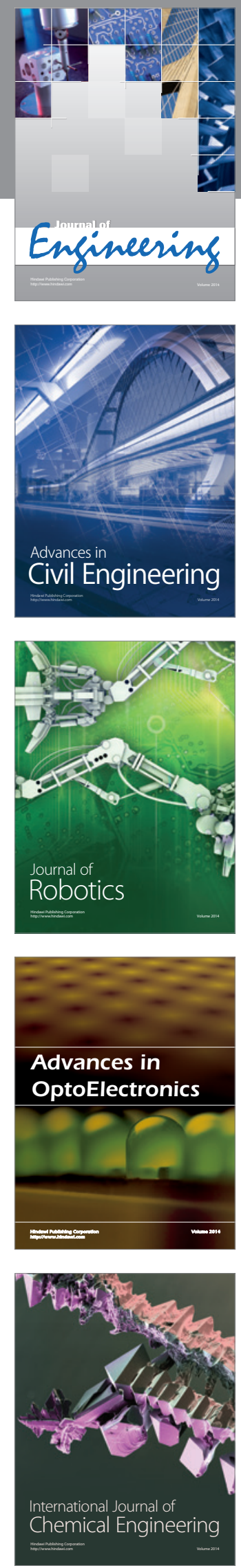

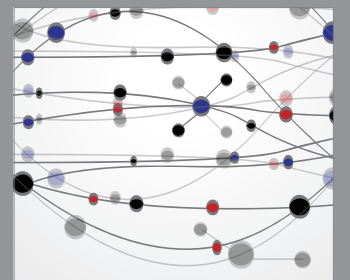

The Scientific World Journal
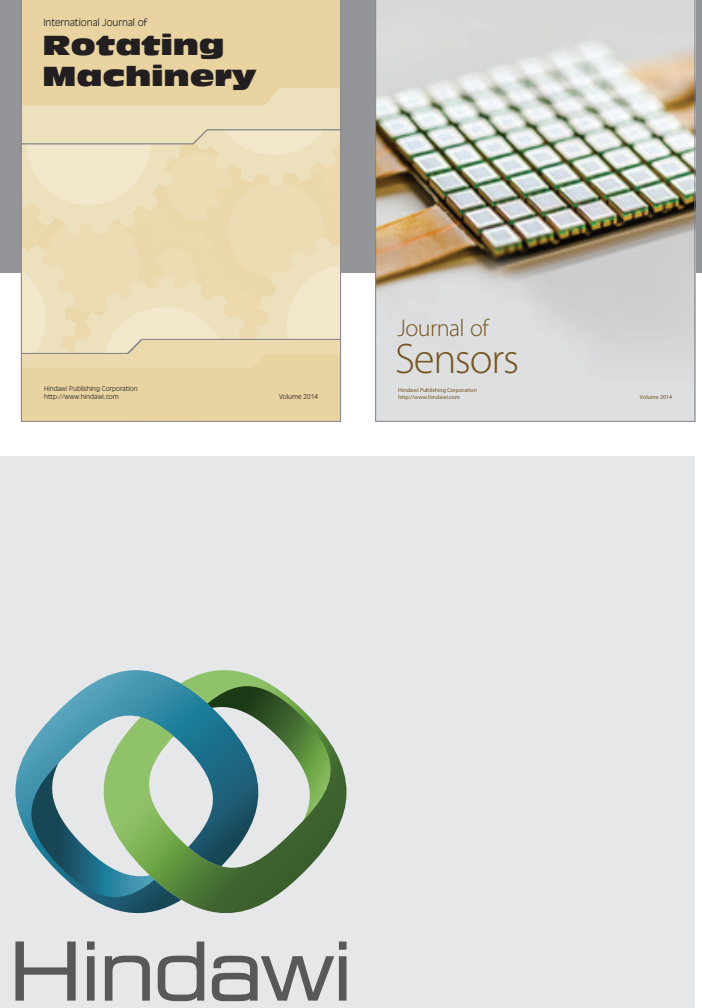

Submit your manuscripts at http://www.hindawi.com
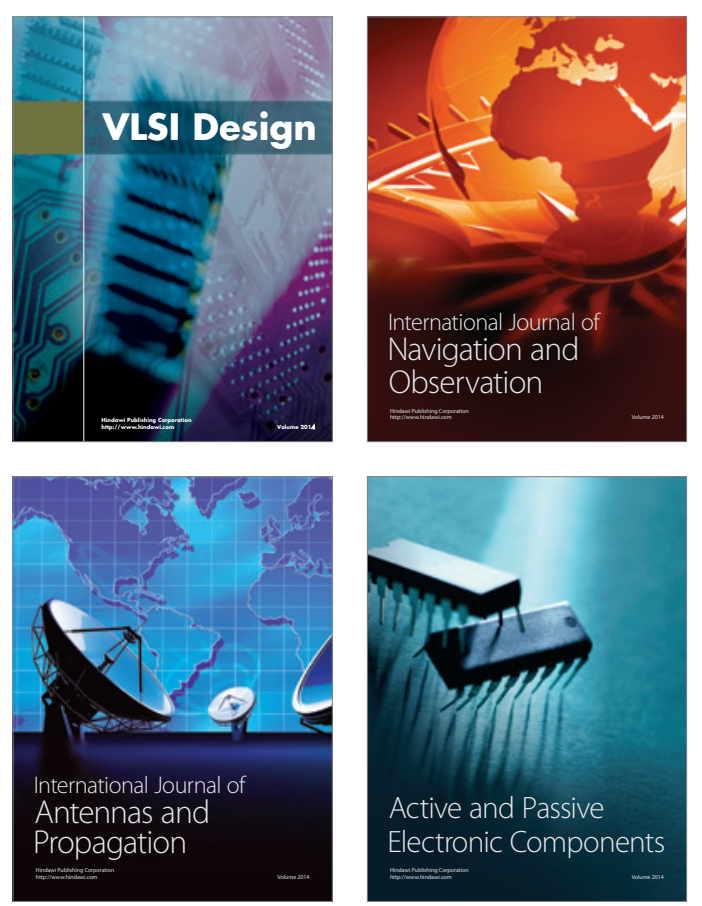
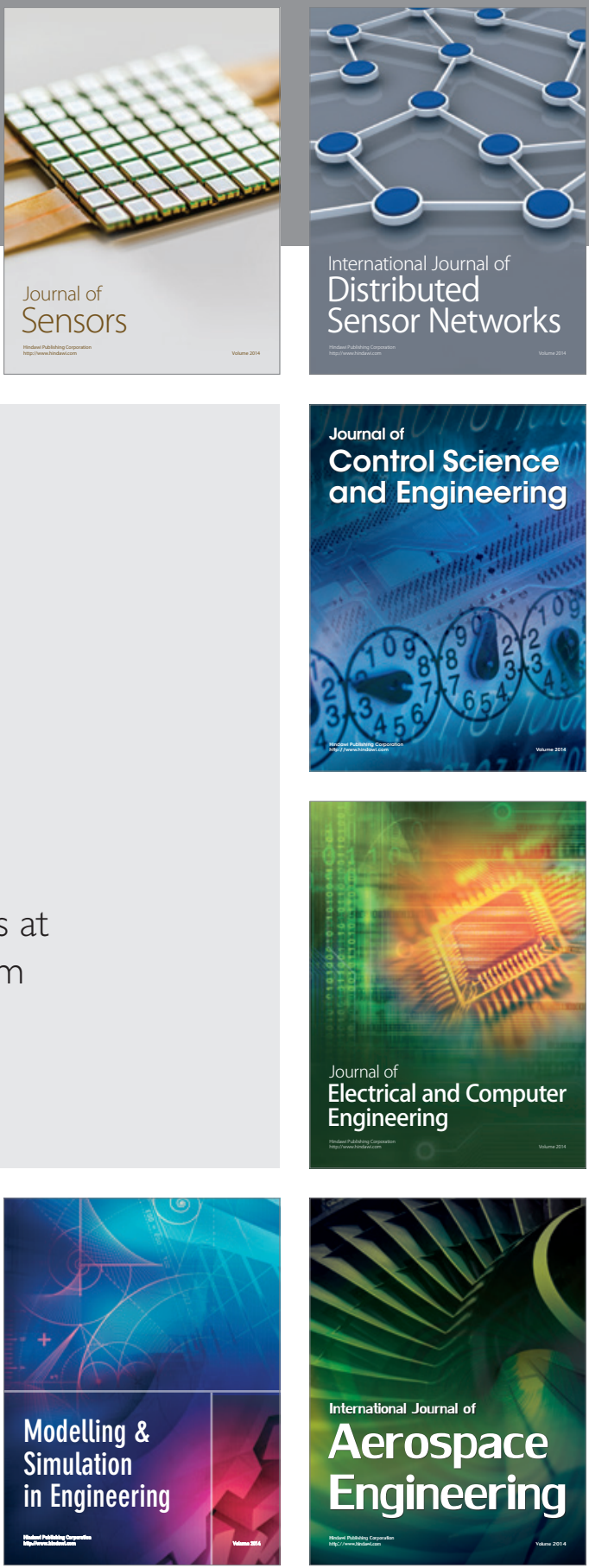

Journal of

Control Science

and Engineering
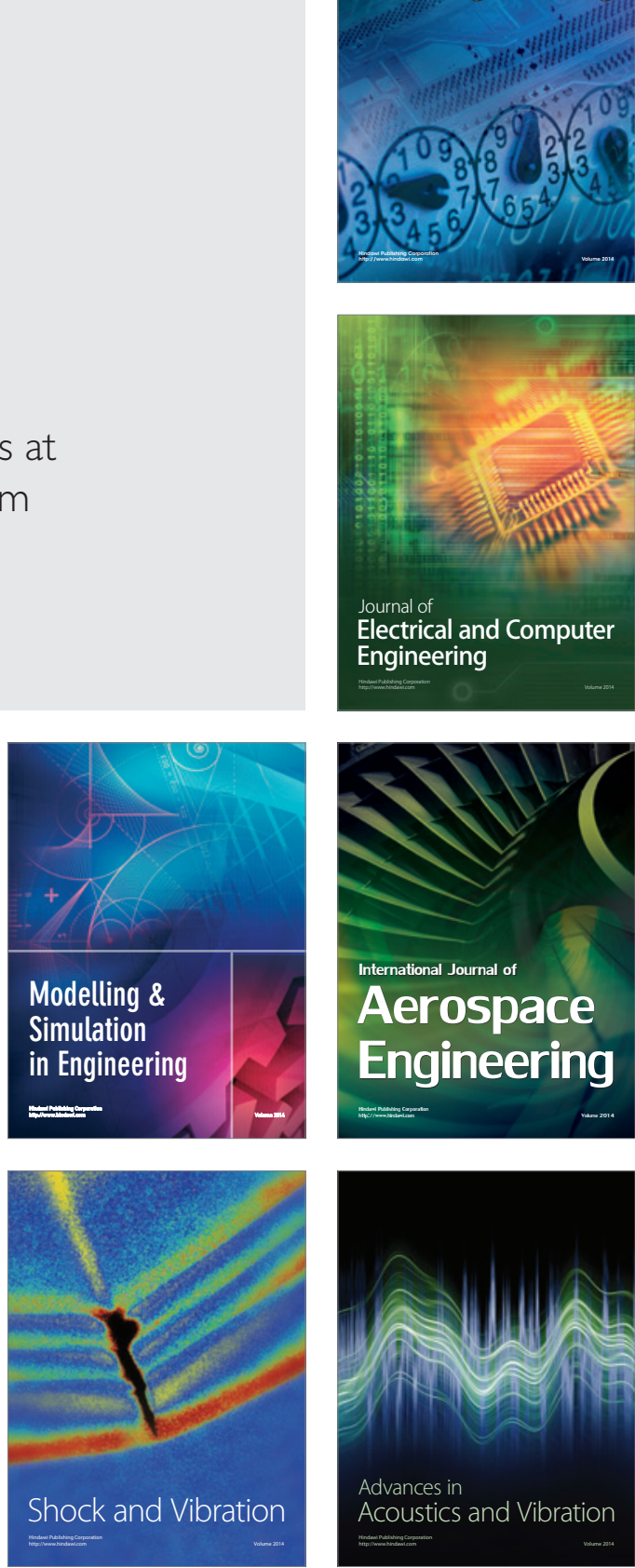